\title{
ANALISA DRUG RELATED PROBLEMS (DRPS) PASIEN GAGAL GINJAL DENGAN KOMPLIKASI DIABETES MELLITUS DI RSUD X
}

${ }^{1}$ Siti Pandanwangi TW, M.M., Apt.

${ }^{2}$ Ahmad Azrul Zuniarto,M Farm,. Apt.

${ }^{3}$ Husni Mubarok, S Farm

\author{
${ }^{1}$ Akademi Farmasi Muhammadiyah Cirebon (sitipandanwangitw@yahoo.com) \\ ${ }^{2}$ Sekolah Tinggi Farmasi YPIB Cirebon (aazuniarto@gmail.com) \\ ${ }^{3}$ RSUD Tegal (mubarok@gmail.com)
}

\begin{abstract}
ABSTRAK
Drug Related Problems (DRPs) merupakan suatu kejadian yang tidak diinginkan atau yang timbul dari suatu terapi pengobatan terhadap pasien. DRPs dapat berupa, ketidaktepatan dosis (lebih tinggi atau lebih rendah dari yang dibutuhkan), interaksi obat DM dengan obat lain, pemilihan jenis obat DM yang kurang tepat, adanya indikasi DM namun tidak mendapatkan terapi obat DM, efek samping obat yang timbul, gagal dalam menerima terapi obat (kepatuhan pasien d1l). Berdasarkan hal tersebut, penulis merasa tertarik untuk mengambil judul "Analisa Drug Related Problems (DRPs) Pasien Gagal Ginjal dengan Komplikasi Diabetes Mellitus di RSUD X ". Jenis penelitian yang digunakan dalam penelitian ini adalah metode analisis deskritif yaitu metode penelitian yang bertujuan mengetahui gambaran Drug Related Problems (DRPs) dari pengobatan injeksi insulin dan Obat Anti Diabetik Oral (OADO) terhadap penurunan fungsi ginjal. Berdasarkan penelitian yang telah dilakukan pada pasien Nefropati Diabetik yang sedang menjalani terapi hemodialisa di RSUD X pada periode bulan januari 2017 sampai dengan bulan mei 2017 diperoleh kesimpulan sebagai berikut :Terdapat 2 (94 \%) pasien yang tidak memperoleh obat gagal ginjal dan $3(81 \%)$ pasien tidak mendapatkan obat DM dari total peresepan yang diterima, hal ini bisa disebabkan tidak terkontrolnya data pasien sebelumnya sehingga terputus pada saat pemeriksaan selanjutnya, dari 16 sampel pasien yang diteliti terjadi 9 pasien mengalami ketidaktepatan pengobatan dengan prosentase $56 \%$. Ketidaktepatan ini berupa pemberian dosis yang sama pada pasien yang sudah ada perbaikan kadar gula darah, hal ini dapat menimbulkan resiko hipoglikemia pada pasien tersebut., hampir seluruh sampel pasien nefropati diabetik mendapatkan dosis berlebih (100\%), hasil pengamatan efek samping obat pada pasien nefropati diabetik pasien mengalami keluhan mual (31\%), pusing (25\%), lemas (94\%), nyeri badan $(31 \%)$, gatal atau alergi $(12.5 \%)$, hasil pengamatan ketidaktepatan pemilihan jenis obat, terdapat 6 sampel pasien yang mengalami ketidaktepatan pemilihan jenis obat dengan prosentase $43,75 \%$. Ketidaktepatan pemilihan jenis obat ini dapat berpengaruh terhadap penurunan fungsi ginjal atau memperberat fungsi ginjal penderita nefropati diabetic, hasil pengamatan interaksi obat diperoleh data interaksi antagonis terjadi $95 \%$ sedangkan untuk interaksi sinergis terjadi 81
\end{abstract}


$\%$, hasil pengamatan pasien tidak menerima obat, diperoleh data bahwa semua pasien memperoleh obat sesuai dengan resep ( $100 \%)$.

Kata kunci: Drug Related Problems (DRPs), penderita nefropati diabetic, rumah sakit X

\begin{abstract}
Drug Related Problems (DRPs) is an undesirable event or arising from a therapeutic treatment of a patient. DRPs may be, inaccurate doses (higher or lower than required), DM drug interactions with other drugs, inappropriate selection of DM drugs, presence of DM indications but not DM drug therapy, adverse drug side effects, failure in receiving drug therapy (patient compliance etc). Based on this, the authors feel interested to take the title "Analysis Drug Related Problems (DRPs) Patients Kidney Failure with Complications of Diabetes Mellitus in RSUD X". Type of research used in this research is descriptive analysis method that is research method which aim to know Drug Related Problems (DRPs) from insulin injection treatment and Oral Anti Diabetic Drug (OADO) to decrease kidney function. Based on the research that has been done on Diabetic Nephropathy patients who are undergoing hemodialysis therapy in RSUD $\mathrm{X}$ in the period of January 2017 up to May7 2017 obtained the following conclusion: There are 2 (94\%) patients who do not get kidney failure drug and $3(81 \%)$ patients did not receive DM medication from total prescribed acceptance, this could be due to uncontrolled patient's previous data so disconnected during subsequent examination, from 16 samples of patients studied occurred 9 patients experiencing treatment inaccuracy with percentage of $56 \%$. This inaccuracy in the form of giving the same dosage to an existing patient improves blood sugar levels, this can lead to the risk of hypoglycemia in these patients., Almost all diabetic nephropathy patients sample get overdose (100\%), observed drug side effects in patients with nephropathy diabetic patients $(31 \%)$, dizziness $(25 \%)$, weakness $(94 \%)$, body aches (31\%), itching or allergies (12.5\%), observation of inaccurate selection of drugs, 6 patients the inaccuracy of the selection of drugs with the percentage of $43.75 \%$. Inaccurate selection of this type of drug may affect the decline in renal function or aggravate the function of kidney patients diabetic nephropathy, the observation of drug interactions obtained by antagonistic interaction data occurred $95 \%$ while for the synergistic interaction occurred $81 \%$, the observation of patients did not receive the drug, obtained data that all patients get the medicine according to the prescription (100\%).
\end{abstract}

Keywords: Drug Related Problems (DRPs), diabetic nephropathy patients, hospital X

\title{
1. PENDAHULUAN
}

Penderita Diabetes Mellitus (DM) rentan terhadap serangkaian komplikasi yang menyebabkan kematian dan kesakitan prematur. Sementara sebagian penderita tidak mengalami gejala ini, sebagian penderita lainnya mengalaminya lebih awal, rata-rata gejala 
komplikasi terlihat jelas pada 15 sampai 20 tahun sejak terjadiya hiperglikemia (harison, 2000).Nefropati diabetik atau penyaki gagal ginjal merupakan penyebab utama kematian atau kecacatan pada Diabetes Mellitus. Nefropati diabetik adalah sindroma klinis pada pasien Diabetes Mellitus yang ditandai dengan albuminuria menetap (>300 mg/24 jam) pada minimal dua kali pemeriksaan dalam kurun waktu 3 sampai 6 bulan (hendromartono, 2006).

Obat-obat Diabetes Mellitus merupakan obat yang harus dikonsumsi secara teratur dan terus menerus, bahkan adakalanya dikonsumsi seumur hidup berkaitan dengan karateristik penyakit Diabetes Mellitus yang tergolong penyakit degeneratif, yang secara langsung dapat berpengaruh juga terhadap Penurunan kondisi ginjal pada penderita Nefropati Diabetik. Namun ada hal hal yang tak bisa disangkal dalam pemberian terapi pengobatan dimana kemungkinan terjadinya hasil pengobatan yang tidak diharapkan atau berpengaruh terhadap peningkatan komplikasi penyakit karena adanya faktor Drug Related Problems (DRPs) dari terapi tersebut.

Drug Related Problems (DRPs) merupakan suatu kejadian yang tidak diinginkan atau yang timbul dari suatu terapi pengobatan terhadap pasien. DRPs dapat berupa, ketidaktepatan dosis (lebih tinggi atau lebih rendah dari yang dibutuhkan), interaksi obat DM dengan obat lain, pemilihan jenis obat DM yang kurang tepat, adanya indikasi DM namun tidak mendapatkan terapi obat DM, efek samping obat yang timbul, gagal dalam menerima terapi obat (kepatuhan pasien dll). Berdasarkan hal tersebut, penulis merasa tertarik untuk mengambil judul "Analisa Drug Related Problems (DRPs) Pasien Gagal Ginjal dengan Komplikasi Diabetes Mellitus di RSUD X”

\section{METODE PENELITIAN}

Jenis penelitian yang digunakan dalam penelitian ini adalah metode analisis deskritif yaitu metode penelitian yang bertujuan mengetahui gambaran Drug Related Problems (DRPs) dari pengobatan injeksi insulin dan Obat Anti Diabetik Oral (OADO) terhadap penurunan fungsi ginjal.

Populasi dalam penelitian ini adalah, pasien dengan diagnosa Nefropati atau Gagal Ginjal di Unit Haemodialisa Rumah Sakit Umum Daerah X pada periode Januari 2017 sampai Mei 2017 Sampel adalah bagian yang diambil dari populasi (Sudjana, 1996). Sampel dalam 
penelitian ini adalah pasien dengan diagnosa Nefropati Diabetes (ND) di unit haemodialisa Rumah Sakit Umum Daerah X pada periode Januari 2017 sampai dengan Mei 2017.

\begin{abstract}
Alat
Wawancara adalah suatu metode yang digunakan untuk mengumpulkan data dimana peneliti mendapatkan keterangan atau pendirian secara lisan dari serorang sasaran penelitian (responden) atau bercakap-cakap berhadapan muka dengan orang tersebut (DR Soekidjo, 2002). Pada penelitian ini digunakan alat wawancara yang dilakukan kepada 16 orang responden penderita nefropati diabetes yang menjalani terapi haemodialisa di RSUD X
\end{abstract}

\title{
Bahan
}

Bahan penelitian yang digunakan dalam penelitian ini adalah register Nefropati Diabetes unit haemodialisa berisi hasil pencatatan petugas unit haemodialisa di RSUD X yang meliputi data kualitatif, yaitu : Kelengkapan data pasien (seperti umur, jenis kelamin, berat badan, riwayat penyakit sebelumnya, serta riwayat penyakit keluarga),jenis obat yang digunakan untuk terapi pengobatan Nefropati Diabetes di RSUD X beserta dosis yang diberikan masing-masing pasien.,data hasil uji laboratorium pasien Nefropati Diabetes pada kurun waktu bulan Januari 2017sampai dengan Mei 2017, data penunjang lainnya seperti data keperawatan di unit haemodialisa

\section{Langkah kerja}

Menetapkan sampel uji penderita Nefropati Diabetes dari total seluruh pasien penderita Nefropati di unit haemodialisa RSUD X periode bulan Januari 2017 sampai dengan Juni 2017, mengambil sampel pasien dari total sampel penderita Nefropati Diabetes yang menggunakan terapi obat injeksi insulin dan OADO atau kombinasi terapi keduanya, engambilan data hasil uji laboratorium penunjang berupa hasil uji nilai kreatinin, nilai ureum, kadar glukosa darah, menetapkan tingkat keparahan kondisi ginjal/grade gagal ginjal dengan menggunakan metode pengukuran LFG/GFR (Laju Filtrasi Glomerlural/Glomelural Filtrate Rate), Melakukan evaluasi terhadap terjadinya Drug Related Problems (DRP's) meliputi :

a. Pasien terindikasi gagal ginjal dengan komplikasi Diabetes Mellitus tetapi tidak memperoleh obat 
b. Pasien gagal ginjal tanpa komplikasi Diabetes Mellitus mendapatkan obat

c. Ketidaktepatan pemilihan jenis obat Diabetes Mellitus untuk pasien gagal ginjal dengan komplikasi Diabetes Mellitus

d. Kelebihan dosis obat anti Diabetes Mellitus

e. Kekurangan dosis obat anti Diabetes Mellitus

f. Terjadinya interaksi obat anti Diabetes Mellitus

g. Reaksi efek samping obat yang muncul

h. Kegagalan memperoleh terapi obat anti Diabetes Mellitus

\section{HASIL DAN PEMBAHASAN}

\section{- Hasil Penelitian}

1. Ketepatan Obat Pasien Nefropati Diabetik

Tabel Ketepatan Obat Pasien Nefropati Diabetik

\begin{tabular}{llllll}
\hline No & Jumlah Peresepan & $\begin{array}{l}\text { Obat Gagal } \\
\text { Ginjal }\end{array}$ & Ket & Obat DM & Ket \\
\hline 1 & 5 & 5 & $100 \%$ & 4 & $80 \%$ \\
2 & 5 & 5 & $100 \%$ & 2 & $40 \%$ \\
3 & 5 & 5 & $100 \%$ & 5 & $100 \%$ \\
4 & 6 & 4 & $66 \%$ & 6 & $100 \%$ \\
5 & 5 & 5 & $100 \%$ & 5 & $100 \%$ \\
6 & 5 & 5 & $100 \%$ & 5 & $100 \%$ \\
7 & 5 & 5 & $100 \%$ & 5 & $100 \%$ \\
8 & 5 & 5 & $100 \%$ & 5 & $100 \%$ \\
9 & 5 & 5 & $100 \%$ & 5 & $100 \%$ \\
10 & 5 & 5 & $100 \%$ & 4 & $80 \%$ \\
11 & 5 & 5 & $100 \%$ & 5 & $100 \%$ \\
12 & 5 & 5 & $100 \%$ & 5 & $100 \%$ \\
13 & 5 & 5 & $100 \%$ & 5 & $100 \%$
\end{tabular}




$\begin{array}{llllll}14 & 5 & 5 & 100 \% & 5 & 100 \% \\ 15 & 5 & 5 & 100 \% & 5 & 100 \% \\ 16 & 5 & 5 & 100 \% & 5 & 100 \%\end{array}$

Hampir Semua pasien penderita nefropati diabetes mendapatkan obat utama terapi utama gagal ginjal hanya pada sampel pasien no 4 dari 6 peresepan 2 kali tidak mendapatkan obat Gagal ginjal dikarenakan faktor tidak terkontrrolnya terhadap rekam medis pengobatan sebelumnya prosentase ketepatan 93,75\% dan untuk obat diebetes mellitus (DM) terdapat 3 pasien yang tidak mendapatkan resep obat DM dari total peresepan yang diterima yaitu pada sampel pasien No 1 (80\%), 2 (40\%) dan $10(80 \%)$ dari hasil tersebut prosentase ketepatan obat DM sebesar $81 \%$.

2. Ketidaktepatan pemilihan obat pasien Nefropati Diabaetik

Tabel Ketidaktepatan Pemilihan Obat

\begin{tabular}{llll}
\hline No & Jumlah item obat & Obat yang tidak sesuai & ket \\
\hline 1 & 8 & - & $0 \%$ \\
2 & 11 & 1 & $9 \%$ \\
3 & 7 & - & $0 \%$ \\
4 & 12 & 2 & $17 \%$ \\
5 & 10 & - & $0 \%$ \\
6 & 5 & - & $0 \%$ \\
7 & 12 & 2 & $17 \%$ \\
8 & 8 & - & $0 \%$ \\
9 & 15 & 2 & $13 \%$ \\
10 & 13 & - & $0 \%$ \\
11 & 6 & - & $0 \%$ \\
12 & 6 & - & $0 \%$
\end{tabular}



136
$0 \%$
149
1
$11 \%$
159
1
$11 \%$
$16 \quad 6$
$0 \%$

Dari total sampel pasien yang diteliti terdapat 6 pasien yang mendapatkan obat yang tidak sesuai dengan kondisi pasien yang sedang mengalami kejadian nefropati diabetik yaitu pada No sampel 2 (9\%), 4(17\%), 7 (17\%), $9(13 \%), 14(11 \%), 15(11 \%)$ dari hasil tersebut prosentase ketidaktepatan pemilihan obat yang terjadi sejumlah $43,75 \%$.

Ketidaktepatan pemilihan obat dari hasil pengamatan berupa Pemberian obat antinyeri golongan NSAID yang dikontraindikasikan atau mempunyai efek memperburuk terhadap kerja dari ginjal. Pengunaan obat DM (metformin $\mathrm{HCl}$ ) yang apabila digunakan dalam jangka panjang dapat memperburuk kinerja dari ginjal (peningkatan asam laktat dalam darah sehingga menganggu metabolisme elektrolit tubuh). Pemberian terapi dengan Allopurinol yang tidak terkontrol yang dapat menimbulkan resiko hipoglikemia pada penderita. Penggunaan suplemen

\section{Ketepatan Dosis}

Tabel Ketepatan Dosis

\begin{tabular}{|c|c|c|c|c|c|}
\hline \multirow[t]{2}{*}{$\mathrm{No}$} & \multirow[t]{2}{*}{ Jumlah item obat } & \multicolumn{3}{|c|}{ Dosis } & \multirow[t]{2}{*}{ Ket } \\
\hline & & lebih & Kurang & tepat & \\
\hline \multirow[t]{2}{*}{1} & 8 & 7 & - & 1 & $87,5 \%$ lebih \\
\hline & & & & & $12,5 \%$ tepat \\
\hline \multirow[t]{2}{*}{2} & 11 & 10 & - & 1 & $91 \%$ lebih \\
\hline & & & & & $9 \%$ tepat \\
\hline 3 & 7 & 7 & - & - & $100 \%$ lebih \\
\hline 4 & 12 & 12 & - & - & $100 \%$ lebih \\
\hline 5 & 10 & 10 & - & - & $100 \%$ lebih \\
\hline
\end{tabular}


PharmaXplore

Jurnal Ilmu Farmasi

\begin{tabular}{|c|c|c|c|c|c|}
\hline 6 & 5 & 5 & - & - & $100 \%$ lebih \\
\hline \multirow[t]{2}{*}{7} & 12 & 11 & - & 1 & $92 \%$ lebih \\
\hline & & & & & $8 \%$ tepat \\
\hline \multirow[t]{2}{*}{8} & 8 & 7 & - & 1 & $87,5 \%$ lebih \\
\hline & & & & & $12,5 \%$ tepat \\
\hline 9 & 15 & 15 & - & - & $100 \%$ lebih \\
\hline 10 & 13 & 13 & - & - & $100 \%$ lebih \\
\hline \multirow[t]{2}{*}{11} & 6 & 5 & - & 1 & $83 \%$ lebih \\
\hline & & & & & $17 \%$ tepat \\
\hline 12 & 6 & 6 & - & - & $100 \%$ lebih \\
\hline 13 & 6 & 6 & - & - & $100 \%$ lebih \\
\hline \multirow[t]{2}{*}{14} & 9 & 8 & - & 1 & $89 \%$ lebih \\
\hline & & & & & $11 \%$ tepat \\
\hline 15 & 9 & 9 & - & - & $100 \%$ lebih \\
\hline 16 & 6 & 6 & - & - & $100 \%$ lebih \\
\hline
\end{tabular}

ISSN: 2527-5801

Vol. 3 No 1 Mei 2018 
4. Hasil pengamatan drps reaksi efek samping obat

Tabel Efek Samping Obat

\begin{tabular}{|c|c|c|c|c|c|c|}
\hline \multirow{2}{*}{ No } & \multicolumn{5}{|c|}{ Efek Samping } & \multirow{2}{*}{ Ket } \\
\hline & Mual & Pusing & Lemas & Nyeri Badan & Alergi & \\
\hline 1 & - & $\sqrt{ }$ & $\sqrt{ }$ & - & - & Mual : 5 \\
\hline 2 & - & $\sqrt{ }$ & $\sqrt{ }$ & - & - & kejadian \\
\hline 3 & - & - & $\sqrt{ }$ & - & - & $31 \%$ \\
\hline 4 & $\sqrt{ }$ & - & $\sqrt{ }$ & - & $\sqrt{ }$ & \\
\hline 5 & $\sqrt{ }$ & - & $\sqrt{ }$ & - & - & Pusing : 4 \\
\hline 6 & - & - & - & $\sqrt{ }$ & - & Koindion \\
\hline 7 & - & $\sqrt{ }$ & $\sqrt{ }$ & $\sqrt{ }$ & - & Kejadian \\
\hline 8 & - & - & $\sqrt{ }$ & - & - & \\
\hline 9 & $\sqrt{ }$ & $\sqrt{ }$ & $\sqrt{ }$ & $\sqrt{ }$ & - & Lemas : 15 \\
\hline 10 & $\sqrt{ }$ & - & $\sqrt{ }$ & - & - & \\
\hline 11 & - & - & $\sqrt{ }$ & $\sqrt{ }$ & - & $94 \%$ \\
\hline 12 & - & - & $\sqrt{ }$ & - & $\sqrt{ }$ & \\
\hline 13 & - & - & $\sqrt{ }$ & $\sqrt{ }$ & - & Nyeri \\
\hline 14 & - & - & $\sqrt{ }$ & - & - & badan : 5 \\
\hline 15 & $\sqrt{ }$ & - & $\sqrt{ }$ & - & - & Keiadian \\
\hline 16 & - & - & $\sqrt{ }$ & - & - & \\
\hline & & & & & & $31 \%$ \\
\hline & & & & & & Alergi : 2 \\
\hline & & & & & & Kejadian \\
\hline & & & & & & $12.5 \%$ \\
\hline
\end{tabular}

Berdasarkan data quesioner dan wawancara dengan pasien/keluarga pasien, petugas hemodialisa, pasien mengeluhkan mual (31\%), pusing (25\%), lemas (94\%), nyeri badan(31\%), gatal atau alergi $(12.5 \%)$. 
5. Interaksi Obat

Tabel Interaksi Obat

\begin{tabular}{ccccl}
\hline No & Obat Yang Diberikan & $\begin{array}{c}\text { Interaksi } \\
\text { antagonis }\end{array}$ & $\begin{array}{c}\text { Interaksi } \\
\text { sinergis }\end{array}$ & \multicolumn{1}{c}{ Ket } \\
\hline 1 & 8 & 3 & 2 & -Interaksi \\
2 & 11 & 9 & 3 & antagonis : 15 \\
3 & 7 & 4 & 2 & kejadian \\
4 & 12 & 9 & 2 & $94 \%$ \\
5 & 10 & 5 & 4 & -Interaksi \\
6 & 5 & 2 & 1 & sinergis : 13 \\
7 & 12 & 10 & 3 & kejadian \\
8 & 8 & 3 & 2 & $81 \%$ \\
9 & 15 & 10 & 4 & \\
10 & 13 & 7 & 4 & \\
11 & 6 & 3 & - & \\
12 & 6 & - & - & \\
13 & 6 & 1 & - & \\
14 & 9 & 7 & 3 & \\
15 & 9 & 5 & 4 & \\
16 & 6 & 3 & 4 & \\
\hline
\end{tabular}

Interaksi yang terjadi pada pemberian obat pada pasien nefropati diabetik dapat berupa interaksi yag bersifat antagonis (merugikan) ataupun yang bersifat sinergis (menguntungkan) dalam pengobatan. Prosentase interaksi antagonis yang terjadi $94 \%$ sedangkan prosentase interaksi yang bersifat sinergis terjadi $81 \%$.

6. Hasil pengamatan drps pasien gagal menerima obat

Dari hasil pengamatan Tidak terdapat Nefropati diabetik yang tidak menerima obat. Seluruh pasien memperoleh pengobatan sesuai dengan resep. Dari hasil pengamatan diperoleh pasien tidak mengalami gagal menerima obat. Seluruh pengobatan pasien ditanggung pihak BPJS dan asuransi kesehatan sejenis,sehingga obat yang dbutuhkan 
pasien dapat terpenuhi.Dari tabel pemberian obat diperoleh data, beberapa pasien tidak disiplin dalam mengkonsumsi obat nefropati diabetik, ketidakpatuhan pengobatan berupa pola pemberian obat yang tidak tepat waktu, pengobatan ulang terapi yang mundur dari tanggal seharusnya pasien sudah kembali untuk konsultasi dengan dokter sehingga pengobatan mengalami kekosongan dari pengobatan sebelumnya, pasien tidak meminum obat yang diberikan dengan alasan malas atau mual.

7. Ketidaktepatan pengobatan

Tabel ketidaktepatan pengobatan

\begin{tabular}{cccl}
\hline No & Jumlah item obat & Obat yang tidak sesuai & Keterangan \\
\hline 1 & 8 & 1 & $12,5 \%$ Gliklazid \\
2 & 11 & 1 & $9 \%$ Gliquidone \\
3 & 7 & 1 & $14,3 \%$ Gliklazid \\
4 & 12 & 2 & $17 \%$ Gliquidone \\
& & & Metformin \\
5 & 10 & 1 & $10 \%$ Gliquidone \\
6 & 5 & 1 & $20 \%$ Gliquidone \\
7 & 12 & - & - \\
8 & 8 & - & - \\
9 & 15 & - & - \\
10 & 13 & - & - \\
11 & 6 & 1 & $17 \%$ Lantus \\
12 & 6 & - & - \\
13 & 6 & - & - \\
14 & 9 & 2 & $22 \%$ Metformin \\
15 & 9 & - & Novomix \\
& & & \\
\hline
\end{tabular}

Dari hasil pengamatan didapat data dari 16 sampel pasien yang diteliti 9 pasien mengalami kejadian ketidaktepatan pengobatan dimana sebagian besar kondisi kadar gula pasien sudah turun atau mengalami perbaikan akan tetapi masih diberikan obat diabetes baik dalam bentuk insulin maupun obat oral diabetes dalam dosis yang sama tanpa dilakukan penyesuain dengan kadar gula dari hasil pemeriksaan laboratorium terbaru .Prosentase kejadian $56 \%$. Dari pengamatan resep yang diperoleh seluruh pasien nefropati diabetik, terdapat beberapa interaksi 
yang terjadi antara obat terapi gagal ginjal dengan obat penyerta lainnya, baik yang bersifat sinergis maupun antgonis interaksi.

Reaksi interaksi dapat berupa efek samping terhadap pasien yang merupakan hal yang sering terjadi dalam pengobatan. Reaksi efek samping dari interaksi obat dapat diminimalisir dengan mengganti terapi pengobatan menggunakan obat yang mempunyai efektivitas yang sama dengan obat pertama, atau dengan mengatur pola pemberian obat berdasarkan waktu pemberian yang tepat.

\section{PENUTUP}

\section{Kesimpulan}

Berdasarkan penelitian yang telah dilakukan pada pasien Nefropati Diabetik yang sedang menjalani terapi hemodialisa di RSUD X pada periode bulan januari 2017 sampai dengan bulan mei 2017 diperoleh kesimpulan sebagai berikut :Terdapat 2 (94\%) pasien yang tidak memperoleh obat gagal ginjal dan $3(81 \%)$ pasien tidak mendapatkan obat DM dari total peresepan yang diterima, hal ini bisa disebabkan tidak terkontrolnya data pasien sebelumnya sehingga terputus pada saat pemeriksaan selanjutnya, dari 16 sampel pasien yang diteliti terjadi 9 pasien mengalami ketidaktepatan pengobatan dengan prosentase $56 \%$. Ketidaktepatan ini berupa pemberian dosis yang sama pada pasien yang sudah ada perbaikan kadar gula darah, hal ini dapat menimbulkan resiko hipoglikemia pada pasien tersebut., hampir seluruh sampel pasien nefropati diabetik mendapatkan dosis berlebih (100\%), hasil pengamatan efek samping obat pada pasien nefropati diabetik pasien mengalami keluhan mual (31\%), pusing (25\%), lemas (94\%), nyeri badan $(31 \%)$, gatal atau alergi $(12.5 \%)$, hasil pengamatan ketidaktepatan pemilihan jenis obat, terdapat 6 sampel pasien yang mengalami ketidaktepatan pemilihan jenis obat dengan prosentase $43,75 \%$. Ketidaktepatan pemilihan jenis obat ini dapat berpengaruh terhadap penurunan fungsi ginjal atau memperberat fungsi ginjal penderita nefropati diabetic, hasil pengamatan interaksi obat diperoleh data interaksi antagonis terjadi $95 \%$ sedangkan untuk interaksi sinergis terjadi 81 $\%$, hasil pengamatan pasien tidak menerima obat, diperoleh data bahwa semua pasien memperoleh obat sesuai 


\section{Saran}

Dilakukan penelitian lebih lanjut tentang analisa interaksi obat dihubungkan dengan obat obat yang digunakan untuk pasien hemodialisa

\section{DAFTAR PUSTAKA}

Ahmad .H. Asdie, 2000. Harrison Prinsip-Prinsip Ilmu Penyakit Dalam, Volume 13, Jakarta : EGC

American Diabetes Association. 2005. Standards of Medical Care For Patients With Diabetes Mellitus. Diabetes Care : PP. 616-623

Anonim. 2005. Departemen Kesehatan RI Direktorat Bina Farmasi Komunitas Klinik.

Arikunto.S. 2006. Proses Penelitian : Suatu Pendekatan Praktek.. Jakarta ; PT.Rineke Cipta

Bagian Kedokteran Universitas Indonesia. 2007. Farmakologi Dan Terapi; Edisi V ; Jakarta.

Cipolle, RJ, Strand, L.M., Morley P.C. 1998. Pharmaceutical Care Practice The Clinician's Guide, Second Edition, 73-119, Mcgraw-Hill, New York

HARKNESS, Richard., 1989. Interaksi Obat, diterjemahkan oleh Goeswin Agoes dan Mathilda B. Widianto. Penerbit ITB ; Bandung

Hendromartono, 2006. Diabetes Mellitus di Indonesia, Dalam : Aru W, dkk, editors, Ilmu Penyakit Dalam, Jilid III, Edisi 4., Jakarta : FK UI

Hoon Tjay, Tan, Drs.Kirana Raharja, 2013. Obat-obatan penting khasiat dan penggunaan dan efek samping : PT. Elek Media Komputindo ; Jakarta.

Ikatan Apoteker Indonesia. 2012. ISO (Informasi Spesialite Obat) Indonesia, Volume 47, Jakarta : PT. ISFI Penerbitan.

Mahmoud M.A. 2008. Drug Therapy Problems And Quality Of Life In Patients With Chronic kidney Disease. University Sains Malaysia.

Medscape, 2017, Drug Interaction Checker, (online), (http://www.reference.medscape.com/drug-interactionchecker), diakses tanggal 9 Desember 2017.

Notoadmodjo, Soekidjo. 2005, Metodelogi Penelitian Kesehatan, Jakarta; PT.Rineka Cipta. 
Parfati, Budisutio, F.H., \& Tan, C.K., 2003,Farmakokinetik Klinik, Dalam Aslam Farmasi Klinis: Menuju Pengobatan Rasional Dan Penghargaan Pilihan Pasien 2003, jakarta, PT.Elek Media Komputindo Gramedia

PCNE. (2010). PCNE Classification For Drug Related Problems. Pharmaceutical Care Network Eurepe Foundation,V6.2 Revised 14-01-2010 Vm, 1-9

PCNE. (2010). PCNE Classification For Drug Related Problems. Pharmaceutical Care Network Eurepe Foundation, V6.2 Revised 14-01-2010 Vm, 1-9

Perkeni. 2006. Konsensus Pengelolaan Dan Pencegahan Diabetes Mellitus Tipe 2 di Indonesia. Naskah Lengkap Pendidikan Kedokteran Berkelanjutan. Ilmu Penyakit Dalam 2006, Surabaya

Stocley, I.H., 2008. Stocley's Drug Interaction. Edisi Kedelapan. Great Britain : Pharmaceutical Press.

Sudjana. 1996. Metode Statistik, Edisi Lima, Bandung ; Alfa Beta Bandung.

Sugiyono. 2006. Statistik Untuk Penelitian, Bandung ; Alfa Beta Bandung.

Sugiyono. 2012. Metodelogi Penelitian Pendidikan, Bandung ; Alfabeta Bandung.

Suhartono T., 2004. Naskah Lengkap PB Persadia. Simposium Diabetes Mellitus Untuk Dokter Dan Diabetisi. Semarang ; Universitas Diponegoro, pp 25-31

Sukandar, E., 2006. Tinjauan Umum Nefropati Diabetik In Nefropati Klinik. Edisi ke-2. Penerbit ITB. Bandung. Hal 274-281

Widyati, Dr, 2014. Praktik Farmasi Klinik : Fokus Pada Pharmaceutical Care, Volume 2, Surabaya : Brilian Internasional

Woodley, M., 1995. Pedoman Pengobatan, Yayasan Essentia Medika ; Yogyakarta 